TITLE:

\title{
ANCHICALLGUS NAUTILI (WILLEY), A CALIGID COPEPOD PARASITIC ON NAUTILUS IN PALAU, WITH DISCUSSION OF CALIGULINA HEEGAARD, 1972
}

\section{$\operatorname{AUTHOR}(S)$ :}

Ho, Ju-shey

\section{CITATION:}

Ho, Ju-shey. ANCHICALLGUS NAUTILI (WILLEY), A CALIGID COPEPOD PARASITIC ON NAUTILUS IN PALAU, WITH DISCUSSION OF CALIGULINA HEEGAARD, 1972.

PUBLICATIONS OF THE SETO MARINE BIOLOGICAL LABORATORY 1980, 25(1-4): 157-165

ISSUE DATE:

1980-02-29

URL:

http://hdl.handle.net/2433/175987

RIGHT: 


\title{
ANCHICALLGUS NAUTILT (WILLEY), A GALIGID GOPEPOD PARASITIC ON NAUTILUS IN PALAU, WITH DISGUSSION OF CALIGULINA HEEGAARD, 1972
}

\author{
JU-SHEY HO \\ Department of Biology, California State University, Long Beach California, 90840, U.S.A.
}

With Text-figures $1-4$

In 1896, Arthur Willey reported discovery of a species of Caligus copepod parasitic on the nautili that were collected from New Britain in the South Pacific. A brief note of this finding was published in the Quartery Journal of Microscopical Science and an appended foot-note gave: "Caligus nautili, pending a more detailed description." Four years later, when he reported some of the crustaceans collected by Arthur Willey from the South Pacific, Thomass R. R. Stebbing (1900) included in it a full description and illustration of this caligid copepod. It was then called "Anchicaligus nautili (Willey)", a species belonging to a new genus.

Willey (1896) reported that $A$. nautili were present in nearly every individual of nautilus that he had examined. This parasite was reported as a "commensal copepod" by Haven (1972) from Nautilus pompilius in the Philippines. She noted that the copepod was common and numerous on the interior aspect of the ala infundibulae and in the postero-dorsal portion of the funnel.

Anchicaligus nautili is an unusual copepod of the family Caligidae. There are about 380 species of caligid copepods known that are parasite of shallow, coastal water fish or oceanic, pelagic fish. Therefore, being the only species of Caligidae that parasitizes a deep-water molluscan host, $A$. nautili deserves more attention in our research on the biology of the parasitic copepods than it has received so far.

Recently, I had an opportunity of examining a collection of this unusual copepods that were recovered from Nauilus pompilius in Palau by Bruce A. Carlson of the University of Hawaii and Michael V. deGruy of Mid Pacific Marine Laboratory at Eniwetok. Since the original description of $A$. nautili is incomplete and the deposition of the type-material is unknown, it is redescribed here in detail based on the examination of the new material. A discussion on the systematic status of Caligulina Heegaard, 1972 is also included, because it is suspencted that Caligulina ocularis Heegaard is conspecific with $A$. nautili.

I would like to thank Messrs. Bruce A. Carlson and Michael V. deGruy for their kindness and generosity in placing their collection of $A$. nautili at my disposal.

Publ. Seto. Mar. Biol. Lab., XXV(1/4), 157-165, 1980.

(Article 11) 
Redescription of Anchicaligus nautili (Willey, 1896)

(Figs. 1-4)

Material examined: 25 mature females (most of them ovigerous), 1 juvenile female, and 2 mature males from Nautilus pompilius collected at Ngemoulis Reef, Palau, on July 1, 1977. Ten females and one male are deposited in the National Museum of Natural History, Smithsonian Institution, Washington, D.C. The remaining specimens are kept in the author's collection.

Female: The cephalothorax (fig. 1A), covered by a subcircular carapace, consists of cephalosome, maxilliped-bearing somite, and the first three pedigerous somites. The frontal region carries a pair of large lunules on its ventral surface. The lateral edge of carapace is fringed with a narrow hyaline membrane. The shallow posterior sinus bears a small membrane on its outer lateral surface. The wide posterior median region of the cephalothorax extends posteriorly well beyond the narrow lateral regions, where there is a semicircular sensory pit. The cephalic area of the carapace is smaller than the thoracic area and bears a pair of large eyes in its anterior region. Each eye has a large oval lens, which, in lateral view, protrudes considerably above the surface of the carapace. The pigment mass of the eye is, unusual in the caligids, much smaller than the lens.

The fourth pedigerous somite (fig. 1A) is distinct from the broad cephalothorax, it has small lateral protrusions to which the fourth legs are attached. The genital complex is fused with the fourth pedigerous somite and exhibits different appearance according to the state of maturity of the eggs contained (compare fig. 1A with fig. 1B). The abdomen is short and broad, and carries a pair of postanal protrusions (fig. 1C) on its posterior surface. The small caudal ramus (fig. 1C) is displaced to the side by the terminal postanal protrusion; it bears the usual six unequal, plumose elements. The egg sacs are short, the longest pair examined is about four-fifths of the body.

The first antenna (fig. 1D) is small and 2-segmented; the first segment is armed with 26 hairy setae on its anterior and distal margins and the second segment, 13 naked setae at the terminal and subterminal surfaces. One of the three long setae situated at the posterodistal corner of the second segment is a bifid element (indicated with arrows in fig. 1D). The second antenna (fig. 1E) is 3-segmented; the basal segment is short and triangular, without posteriorly projecting inner tooth that is seen in many species of Caligus; the middle segment is the largest and unarmed; the terminal segment is modified into a claw and carries two small setae. There is a small postantennal process (fig. 1E) bearing a pair of setules on it and another two pairs in its vicinity.

The mouth tube and mandible are of the usual form seen in Caligus. The first maxilla (fig. 1E) is represented by a bundle of three naked, unequal setae located posteromedial to a weak sclerite. The postoral process (fig. $1 \mathrm{E}$ ) is very much reduced, it is merely a small knob bearing a tiny hyaline process. The 2-segmented second maxilla (fig. 2A) is of the typical Caligus form, with the two terminal processes about equal in length. The maxilliped (fig. 2B) is a powerful, robust, and prehensile appendage; the stout proximal segment is unarmed, but the terminal claw-like segment (fig. 

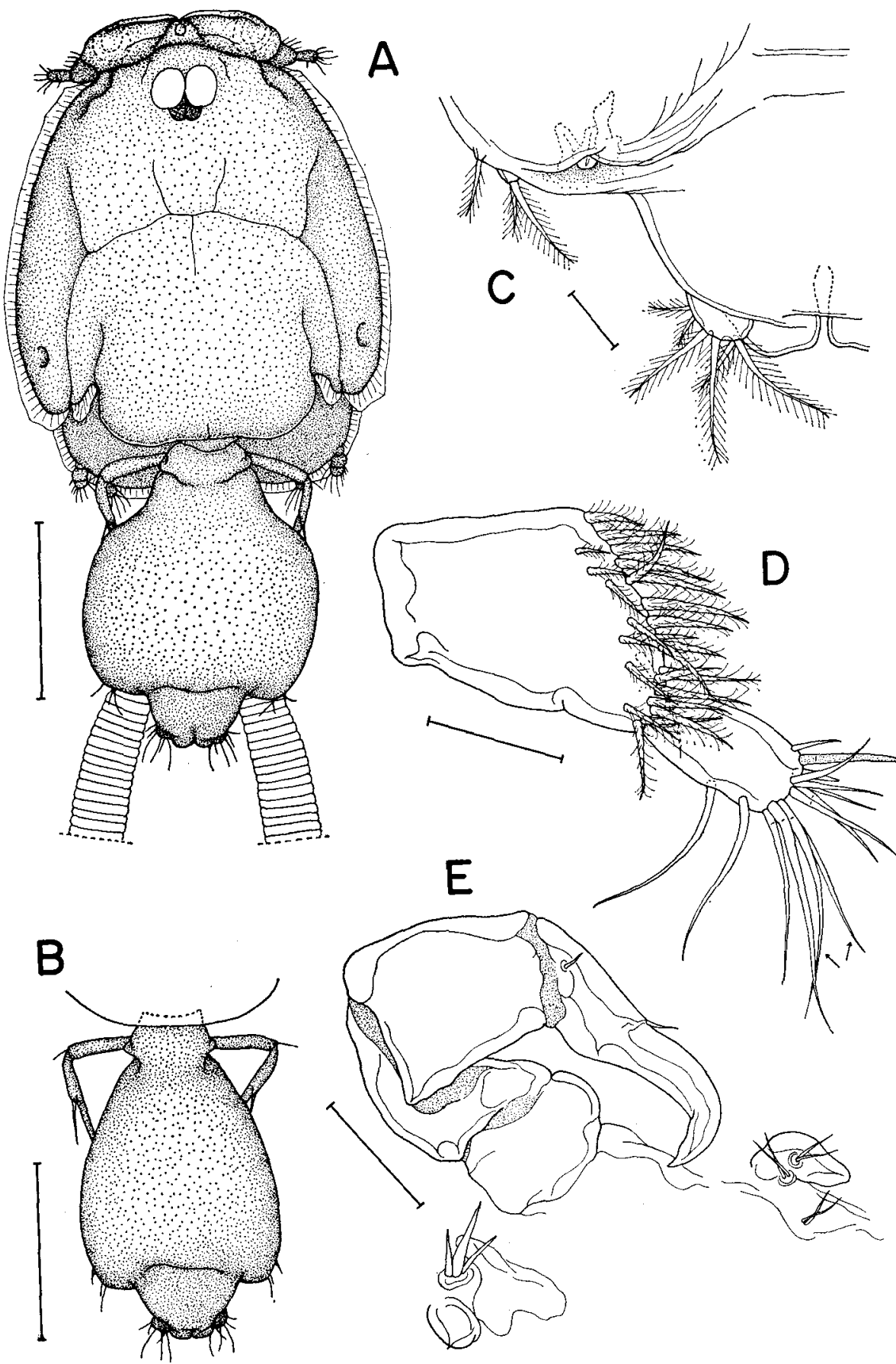

Fig. 1. Anchicaligus nautili (Willey), female. A. body, dorsal. B. genital complex of another specimen, dorsal. C. posterolateral corner of genital complex and abdomen, right side, ventral. D. first antenna, ventral. E. second antenna, postantennal process, and first maxilla. Scale: $1 \mathrm{~mm}$ in $\mathrm{A}, \mathrm{B} ; 0.1 \mathrm{~mm}$ in $\mathrm{C}, \mathrm{D}, \mathrm{E}$. 
2C) bears a seta and a tiny knob slightly distal to the median incomplete suture. There is no sternal furca but an U-shaped intersclerite and two transverse apodemes (fig. 2D).

The armature in legs $1-4$ is as follows (Roman numerals indicate spine and Arabic numerals setae):

\begin{tabular}{|c|c|c|c|}
\hline & Protopod & Exopod & Endopod \\
\hline Leg 1 & $0-0 ; 1-1$ & $1-0 ; \mathrm{I}, \mathrm{III}, 3$ & (rudimentary) \\
\hline Leg 2 & $0-1 ; 1-0$ & $\mathrm{I}-1 ; \mathrm{I}-1 ; \mathrm{II}, \mathrm{I}, 5$ & $0-1 ; 0-2 ; 6$ \\
\hline Leg 3 & $1-1$ & $\mathrm{I}-0 ; \mathrm{I}-1 ; \mathrm{III}, 4$ & $0-1 ; 6$ \\
\hline Leg 4 & $1-0$ & I, III & (absent) \\
\hline
\end{tabular}

The endopod of leg 1 (fig. 3A) is reduced to a small lobe as in all the species of Caligus and the exopod is also like many species of Caligus in having two bifurcate spines on the terminal segment (fig. 3B). Leg 2 (fig. 3C) and leg 3 (fig. 3D) are not much different from that of the Caligus. Leg 4 (fig. $3 \mathrm{E}$ ) is relatively slender and long. It is rather unusual in having the expood distinctly longer than the protopod. The three terminal spines are extremely unequal, with the innermost spine nearly seven times as long as the outermost spine. Leg 5 (fig. 1G) is represented by three small plumose seate on the posteroventral corner of the genital complex near egg sac attachment area. Leg 6 is absent.

Measurements of female (in $\mathrm{mm}$ ): The following measurements are based on ten randomly selected mature females. Total length of body 4.13 (3.53-4.54), carapace width 2.27 (2.03-2.44), carapace length 2.46 (2.21-2.63), width of genital complex 1.18 (1.09-1.31), length of genital complex (including fourth pedigerous segment) 1.38 (1.13-1.54), abdomen width 0.51 (0.37-0.68), and abdomen length 0.32 (0.26$0.38)$. The longest egg sac observed is 3.56 .

Male: Only those features that are different from the female are mentioned in the following.

The genital complex is distinctly smaller than the thoracic area of the carapace (fig. 4A). Both genital segment and abdomen are distinctly wider than long. The genital segment contains a pair of mature spermatophores (fig. 4B). Leg 6 (fig. 4B) is represented by two plumose setae at the tip of the posteroventral ridge of the genital segment. There is a setule located on the edge of the genital complex between leg 5 and leg 6. The first antenna has a longer distal segment, it is 2.3 times longer than wide ( 1.94 times in female). The proximal segment bears 28 hairy setae; the additional two setae are found among the ventrodistal group of setae. The second antenna (fig. 4C) has long and slender first and second segments, the latter bears a large striated area on its inner surface. The third segment (fig. 4D) is short, with bifurcate terminal process bearing unequal tines. There is only one seta at the base of the third segment. The first segment of maxilliped (fig. 4E) is slightly different from that of the female in bearing a small protrusion on the inner surface.

Measurements of male (in $\mathrm{mm}$ ): Total length of body 3.23, carapace width 2.10 , carapace length 2.28, width of genital complex 0.94 , length of genital complex 0.75 , 


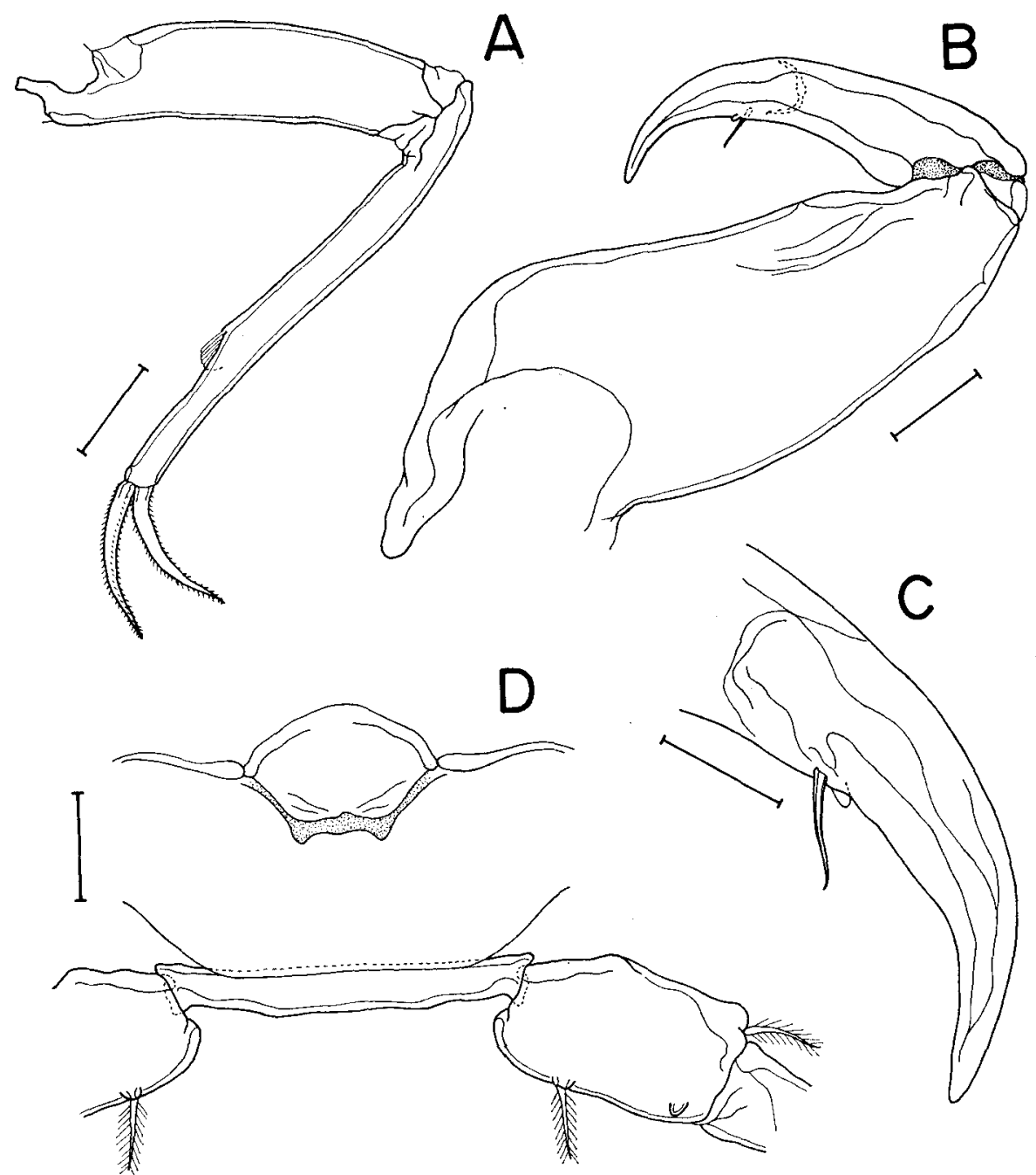

Fig. 2. Anchicaligus nautili (Willey), female. A. second maxilla. B. maxilliped, C. tip of maxilliped. D. sternal area, intercoxal plate, and protopods of leg 1 . Scale: $0.1 \mathrm{~mm}$ in $\mathrm{A}, \mathrm{B}, \mathrm{D} ; 0.05 \mathrm{~mm}$ in $\mathrm{C}$.

abdomen width 0.53 , and abdomen length 0.26 .

Remarks: The most outstanding feature of the present species is the pair of large lenses (conspicillae) in the median eyes. They are reminiscent of those found on the species of sapphirinids and corycaeids-the planktonic cyclopoid copepods. In those planktonic cyclopoids, the two lenses are placed close to the anterior edge of the cephalothorax and with either a short or a considerable distance between them. Although there are some male pandarid copepods occurring in plankton also have a pair of large lenses, they are not as large as those in the present species.

The possession of postanal protrusions resulting in displacement of the caudal 


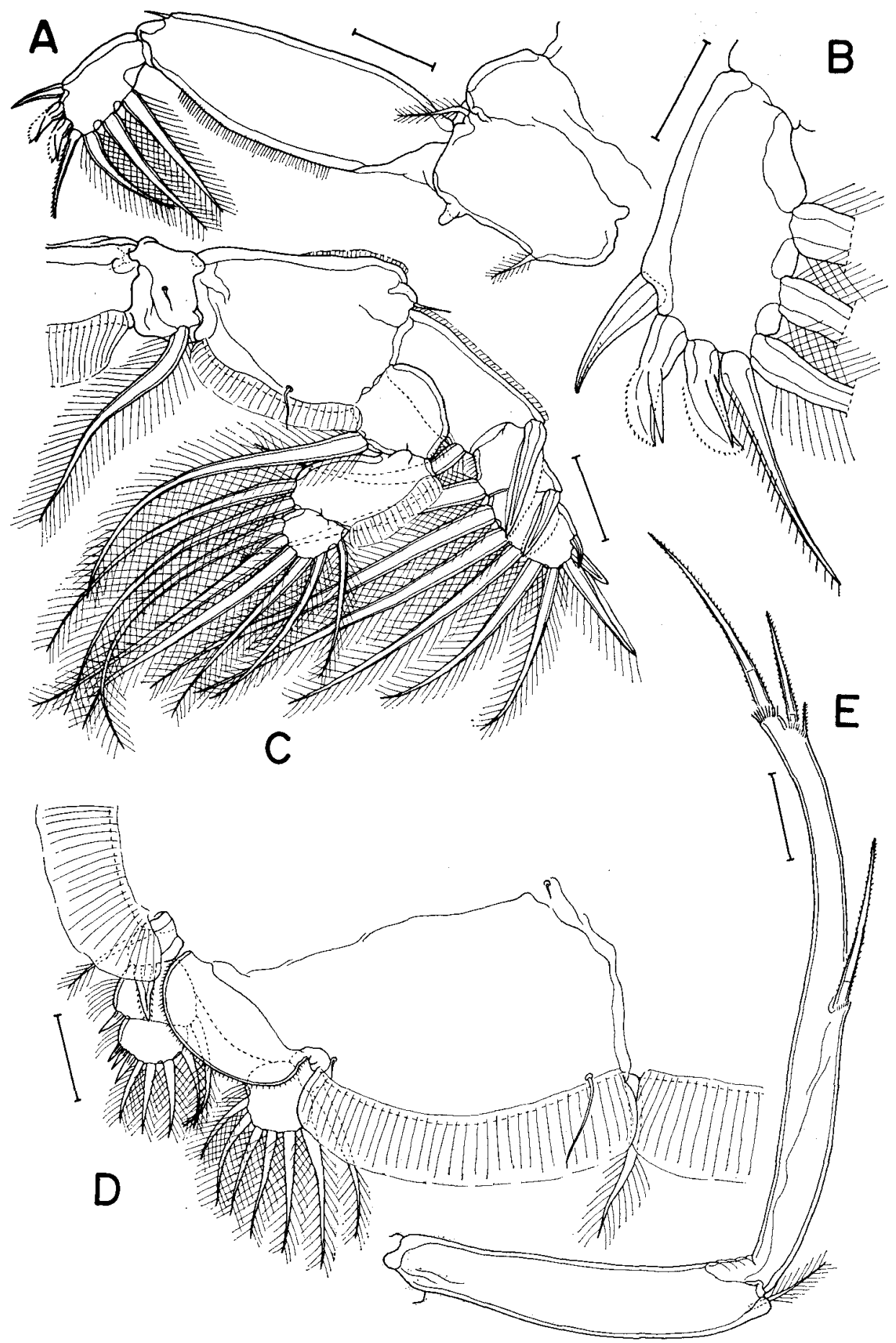

Fig. 3. Anchicaligus nautili (Willey), female. A. leg 1. B. tip of exopod of leg 1 . C. leg 2. D. $\operatorname{leg}$ 3. E. leg 4. Scale: $0.1 \mathrm{~mm}$ in $A, C, D, E ; 0.05 \mathrm{~mm}$ in $B$. 


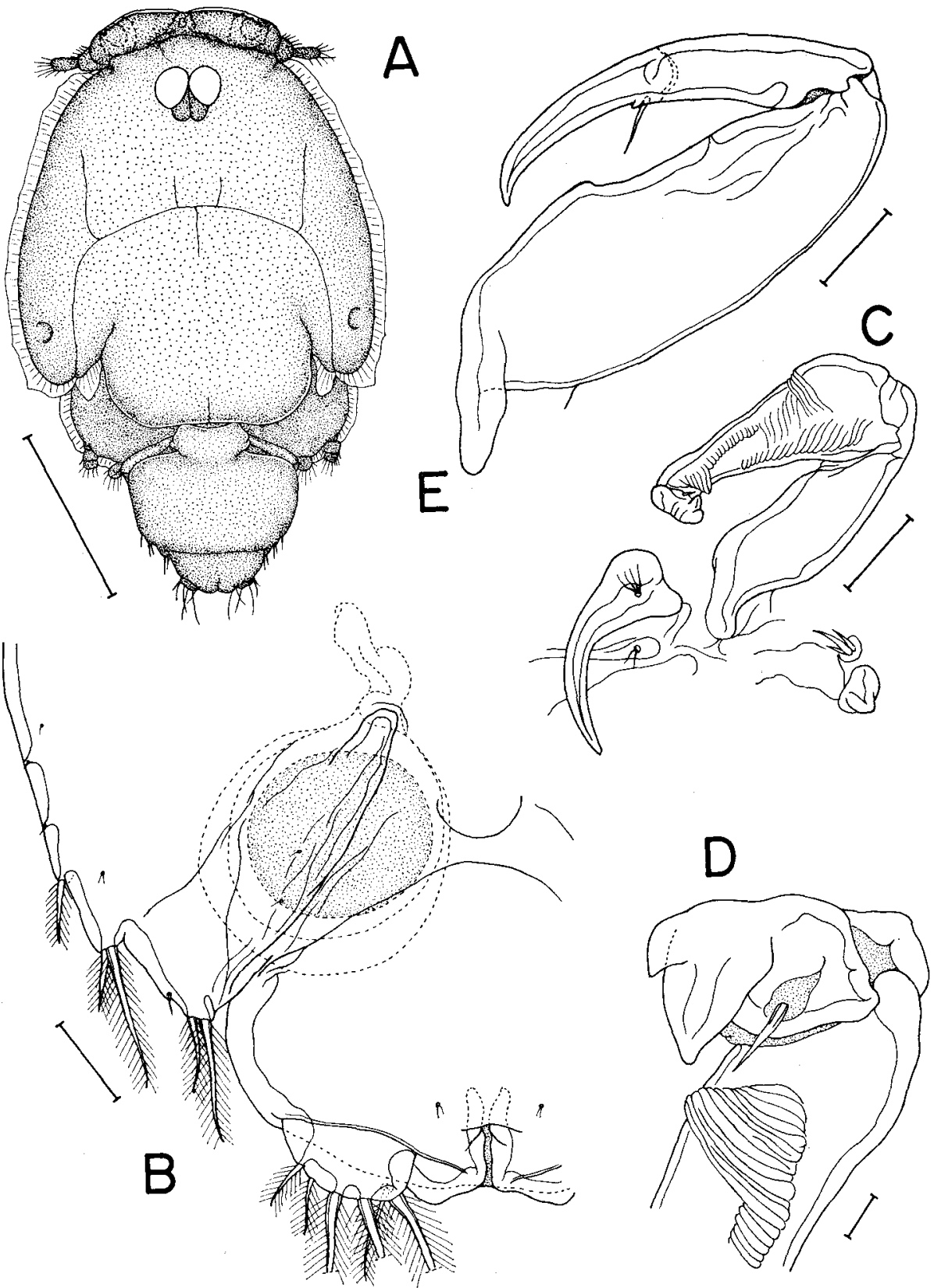

Fig. 4. Anchicaligus nautili (Willey), male. A. body, dorsal. B. posterolateral corner of genital complex and abdomen, right side, ventral. C. second antenna, postantennal process, and first maxilla. D. tip of second antenna. E. maxilliped. Scale: $1 \mathrm{~mm}$ in $A ; 0.1 \mathrm{~mm}$ in $\mathrm{B}, \mathrm{C}, \mathrm{E} ; 0.01 \mathrm{~mm}$ in $\mathrm{D}$. 
rami is another remarkable characteristic of the present species. As far as the structure of appendages are concerned, $A$. nautili is not much different from the species of Caligus.

Discussion of Caligulina Heegaard, 1972

The parasitic copepods of the family Caligidae, as it stands now, contains thirty-one genera. Due to the presence of a pair of distinctive common structures-the lunules, eighteen genera of this family are lumped together under the subfamily Caliginae.

According to Ho and Bashirullah (1977), eight genera in the Caliginae are distinguishable in lacking a sternal furca. Moreover, three of these eight genera, Anchicaligus, Caligulina, and Metacaligus, are different from the remaining five in the possession of a pair of postantennal processes in both sexes, although it is considerably smaller in the female. Therefore, with the combined characteristics of bearing a pair of lunules, missing the sternal furca, and possessing the postantennal processes, Anchicaligus, Caligulina, and Metacaligus seem to fall into a group of closely allied genera in the Caligidae.

The genus Metacaligus, as redefined by Ho and Bashirullah (1977), is distinguishable from both Anchicaligus and Caligulina in the armature of leg 1, leg 2 and leg 4. In Metacaligus, the middle two spines on the terminal segment of the exopod of leg 1 is always bilaterally denticulate and never bifurcate; the last segment of the exopod of leg 2 has two spines (instead of three); and the exopod of leg 4 has five spines (insted of four).

The genus Caligulina was erected by Heegaard (1972) to accommodate a single male caligid that was found in a plankton sample collected from the South China Sea. Heegaard's description and figures of Caligulina ocularis are very close to Anchicaligus nautili in almost every respect. The only significant difference between the two species is the structure of leg 3. This appendage in $C$. ocularis is very unusual for the caligid copepods in that it has a 3-segmented endopod and lacks a claw-like spine on the first segment of the exopod. It is wondered if these extremely unusual anatomical features of leg 3 might be an artifact resulted from a cursorial observation that was made on an undissected, single specimen.

In his letters from New Guinea reporting a field observation of $A$. nautili, Willey (1896) wrote: "When Nautili are placed in jars the Caligids emerge in large numbers from the mantle chamber, and swim about actively in the water,...". And, moreover, Bruce A. Carlson has informed me that the copepods he collected from Palau nautili were found in abundance in.the containers where the nautili were kept immediately after capture. Therefore, it seems that $A$. nautili is capable to leave its host and should be expected to occur in the plankton samples. In fact, several species of Caligus have been reported from both their fish hosts and plankton samples. Since the single specimen of $C$. ocularis obtained pelagically during the Dana Expedition is so close to A. nautili, and Heegaard failed to compare it with $A$. nautili in his remarks on $C$. ocularis, one can not but cast doubt on the validity of the genus Caligulina and its monotypic species ocularis. 


\section{REFERENCES}

Heegaard, P. 1972. Caliginae and Euryphorinae of the Dana Expedition (Crustacea, Copepoda, Caligidae). Steenstrupia, 2(19): 295-317.

Haven, N. 1972. The ceology and behavior of Nautilus pomilius in the Philippines. The Veliger, 15(2): 75-80.

Ho, J.S. and A.K.M. Bashirullah, 1977. Two species of caligid copepods (Crustacea) parasitic on marine fishes of Venezuela, with discussion of Metacaligus Thomsen, 1949. J. nat. Hist., 11: 703-714.

Stebbing, T.R.R., 1900. On Crustacea brought by Dr. Willey from the South Seas. in A. Willey's Zoological Results based on material from New Britain, New Guinea, Loyalty Islands and elsewhere collected during the years 1875, 1896, and 1897, pt. 5: 605-690.

Willey, A. 1896. Letters from New Guinea on Nautilus and some other organisms. Quart. J. Microscop. Sci., 39(154) : 145-180. 